total of 50 contests, the PRF Ss won $38\left(\chi^{2}=13.52\right.$, $\mathrm{p}<.01)$. Thus, prior PRF training in a runway situation tends to produce winners in the tube dominance test.

The transfer of persistence from a nonsocial runway situation to a completely different tube-competition situation is of great theoretical interest. The tube dominance test is essentially an extinction test, because food reward is withheld during the test and the passage is blocked by another animal. The fact that more PRF Ss persisted in approaching the empty endbox can be considered as a manifestation of the PRE. This transfer of the PRE across drastically different situations, and after two sessions of extinction and two sessions of CRF training, further attests to the remarkable durability of the PRE in both strains of mice. This transfer of long-term persistence effects supports Amsel's frustration theory (Amsel, 1967), which attributes the transfer to conditioned anticipatory frustration $\left(\mathrm{r}_{\mathrm{F}}-\mathrm{S}_{\mathrm{F}}\right)$. According to this theory, once an approach response becomes conditioned to $r_{F}-s_{F}$ (i.e., $s_{F} \rightarrow$ approach), whenever $r_{F}-S_{F}$ is conditioned to a subsequent situation, it will mediate the approach response. The present finding also supports the contention that $s_{F} \rightarrow$ approach mechanism does not become dissociated during extinction (e.g., Traupmann et al, 1971).

Viewed from a different angle, it seems that prior PRF training has some effects on aggressive behavior. When the two contestants meet in the center of the tube, they tend to push and sometimes attack each other. It is possible that the PRF Ss are more persistent in "fighting," consequently they win out. If prior PRF training in the runway indeed produces more tenacious "fighters" and more dominant animals, it will provide evidence that effects of PRF training can transfer across different response systems. It will also follow that different histories of reinforcement in a nonsocial learning situation may change the social hierarchy of animals. However, in the present tube test, the effect of prior PRF training on aggressive behavior and social hierarchy cannot be assessed independently of its effects on resistance to extinction.

\section{REFERENCES}

Amsel, A. Partial reinforcement effects on vigor and persistence: Advance in frustration theory derived from a variety of within-subjects experiments. In K. W. Spence and J. T. Spence (Eds.), The psychology of learning and motivation. Vol. 1. New York: Academic Press, 1967, Pp. 1-65.

Amsel, A., Wong, P. T. P., \& Traupmann, K. L. Short-term and long-term factors in extinction and durable persistence. Journal of Experimental Psychology, 1971, 90, 90-95.

Bovet, D., Bovet-Nitti, F., \& Oliverio, A. Genetic aspect of learning and memory in mice. Science, $1969,163,139-149$.

Lindzey, G., Winston, H., \& Manosevitz, M. Social dominance in inbred mouse strains. Nature (London), 1961, 191, 474-476.

Sprott, R. L. Passive-avoidance conditioning in inbred mice: Effects of shock intensity, age and genotype. Journal of Comparative \& Physiological Psychology, 1972, 80, 327-334.

Thompson, W. $R$. The inheritance of behavior: Behavioral differences in fifteen mouse strains. Canadian Journal of Psychology, 1953, 7, 145-155.

Traupmann, K. L., Wong, P. T. P., \& Amsel, A. Durability of persistence as a function of number of partially reinforced trials. Journal of Experimental Psychology, 1971, 88, 372-375.

Wong, P. T. P., Lee, C. T., \& Novier, F. H. The partial reinforcement effect (PRE) sustained through extinction and continuous reinforcement in two strains of inbred mice. Psychonomic Science, 1971, 22, 141-143.

Wong, P. T. P. Traupmann, K. L., \& Brake, S. Does delay of reinforcement produce durable persistence? Quarterly Journal of Experimental Psychology, 1974, 26, 1-11.

\title{
Vowels and consonants as targets in the search of single words*
}

\author{
CARLTON T. JAMES $\dagger$ \\ Rutgers University, New Brunswick, New Jersey 08903
}

\begin{abstract}
Ss searched four- and six-letter words typed in uppercase for predesignated target letters, Reaction times to vowel targets were faster than to consonant targets for both stimulus lengths; this was true whether or not the target was contained in the stimulus word. The results are interpreted to indicate that an early stage in word perception is the location of vowels, as proposed by Hansen and Rogers, 1968.
\end{abstract}

In a study of visual search of lowercase words, James

\footnotetext{
*This research was supported by NSF University Science Development Program, Grant GU 1598, to the University of Texas at A ustin. Preparation of the manuscript was facilitated by support from the Rutgers University Research Council. The author wishes to express his appreciation to David Smith for his assistance and to Kathryn T.Spoehr for her comments.

tRequests for reprints should be sent to Carlton $T$. James, Psychology Department, Rutgers College, New Brunswick, New Jersey 08903.
}

and Smith (1970) found that predesignated vowel targets were found faster than consonant targets. Since the difference disappeared with nonword stimuli, James and Smith concluded that the vowel advantage was somehow connected with the structure of words. They suggested that vowels occur in more predictable orthographic contexts than consonants, and a 
breakdown of their data in terms of hypothetically more constrained environments seemed to provide some support for this explanation.

However, it is possible that visual cues peculiar to lowercase stimuli favor the location of vowels. For example, ascending and descending letters might draw S's attention and cause preceding or succeeding vowels to stand out. Hence, there are (at least) two explanations of the vowel advantage; one is based on visual factors, the other on orthographic (i.e., spelling) rules. A vowel advantage should still be noted when words are typed in capitals only if the orthographic explanation were correct. It has been known (at least since Pillsbury, 1897) that words typed in lowercase provide certain cues for word recognition. Elimination of these cues by using capital letters can change the nature of word recognition; it is, therefore, plausible that elimination of the lowercase cues would destroy the vowel advantage in the search task.

There is some reason for doubting the generality of the vowel advantage, inasmuch as James and Smith failed to find a word-nonword difference. This failure is inconsistent with the bulk of the word recognition literature (cf. Reicher, 1969) and with other letter-search experiments (Krueger, 1970). These studies have typically used uppercase stimuli, raising the possibility that the processes involved in letter search differ depending upon type font. This conclusion will be supported if a vowel advantage is not obtained in search of words typed in uppercase.

\section{METHOD}

\section{Materials}

The same stimuli used by James and Smith in their Experiment I were used here, only typed in uppercase. Eighty four-letter and 120 six-letter words (frequency, 5-31) were selected from Kư̌cera and Francis (1967); no letter occurred more than once in a given word.

The same half of the words (40 four-letter and 60 six-letter) were always used for "yes" judgments. Each word was presented once to each $\mathrm{S}$; each position in every four-letter word was tested three times during the experiment; each position in every six-letter word was tested twice. Each S was tested 10 times on each position of four- and six-letter words, for a total of 100 positive trials. Each $\mathrm{S}$ also received 100 negative trials, in which the target letter did not appear in the stimulus word. In four-letter positive words, there were 74 vowels and 86 consonants; $51 \%$ of the vowels occurred in the first half of the word, compared with 54\% of the consonants. Frequency of vowel and consonant targets for negative trials was the same as for positive trials.

\section{Procedure}

A letter (the target was read aloud) and, approximately $1 \mathrm{sec}$ later, an uppercase word appeared in a tachistoscope, activating a millisecond timer. The word remained in view until S pressed one of two buttons, indicating whether or not the letter was contained in the word. Either response stopped the timer and terminated the presentation.

Twelve University of Texas undergraduates participated in partial fulfillment of a course requirement. Each $S$ received 10
Table 1

Mean Reaction Times (in Milliseconds) for Vowel and Consonant Targets

\begin{tabular}{lccccc}
\hline & \multicolumn{2}{c}{ Positive Trials } & & \multicolumn{2}{c}{ Negative Trials } \\
\cline { 2 - 3 } \cline { 6 - 6 } & $\begin{array}{c}\text { Four } \\
\text { Letters }\end{array}$ & $\begin{array}{c}\text { Six } \\
\text { Letters }\end{array}$ & & $\begin{array}{c}\text { Four } \\
\text { Letters }\end{array}$ & $\begin{array}{c}\text { Six } \\
\text { Letters }\end{array}$ \\
\hline Vowel & 650 & 679 & & 661 & 717 \\
Consonant & 683 & 710 & & 680 & 757 \\
\hline
\end{tabular}

practice trials (five positive, five negative) using five-letter stimuli; instructions emphasized that $S$ s should respond as rapidly as was consonant with accuracy.

\section{RESULTS}

Error rate was negligible, $4.5 \%$ for positive trials, $2.3 \%$ for negative trials. Reaction time data (see Table 1) were analyzed by a 2 by 2 by 2 analysis of variance, where the factors of word length (four or six letters), test type (positive or negative, and target (vowel or consonant) were all within-S factors. Targets were located faster in four-letter than in six-letter words $[F(1,11)=39.94, p<.01]$; reaction times were faster on positive trials $[\mathrm{F}(1,11)=6.30, \mathrm{p}<.05]$; and vowel targets were located faster than consonant targets $[F(1,11)=8.24, \quad p<.05]$. The only significant interaction was between the first two variables $[F(1,11)=6.62, \quad p<.05] ;$ the positive-negative difference was greater for six than for four-letter words. All other interactions were nonsignificant, Fs $<1.00$, indicating that the vowel advantage was not substantially influenced by variations in either length or presence/absence of the target.

All of these results (except the significant interaction) were obtained by James and Smith (Experiment I.) The correlation between average RTs (for vowel and consonant targets) for lowercase and uppercase data (positive trials only) was .715. The vowel advantage is thus not dependent upon the visual environment associated with words typed in lowercase but is obtained even when visual cues specific to lowercase letters are eliminated by typing the words in uppercase.

Since the vowel-consonant difference is not dependent upon type font, one might question the claim that James and Smith's failure to find a word-nonword difference resulted from their use of lowercase stimuli. That failure is perhaps attributable to their between-groups design, wherein each $\mathrm{S}$ was presented only words or nonwords. Most of the word-nonword differences have been obtained in designs where Ss are tested with both types of stimuli. There are two issues raised by the use of the between-groups design, either of which could potentially wash out a word advantage. First, the design is not sensitive to between-groups differences, which are small relative to variability among 
Table 2

Mean Reaction Time (in Milliseconds) for Vowels and Consonants as a Function of Preceding Context (Collapsing Across Position Within the Word)

\begin{tabular}{ccccccc}
\hline & & \multicolumn{3}{c}{ Target } & & \multicolumn{2}{c}{ Vowel } \\
Word & & & \multicolumn{2}{c}{ Consonant } \\
\cline { 2 - 3 } Length & V/V* & V/C & V/CC & & C/V & C/C \\
\hline Four & 648 & 661 & 641 & & 698 & 727 \\
Six & 712 & 694 & 762 & & 735 & 709 \\
\hline
\end{tabular}

*Read "vowel preceded by vowel:"

Ss. Second, search strategies and/or response criteria may differ depending on whether a $S$ received only nonwords or a mixture of words and nonwords. The small difference found by James and Smith supports the latter interpretation. The evidence does not, therefore, justify the postulation of different processes for search of uppercase and lowercase words.

To return to the vowel advantage, James and Smith (1970) hypothesized that orthographic rules predict vowel locations more accurately than consonant locations. Their evidence for this proposition is based on the following argument (p.59): "Whether the target letter is a vowel or a consonant, RT should be faster if the target follows a consonant than if it follows a vowel. In the case of a consonant target, a preceding consonant restricts the set of possible next letters more than does a preceding vowel. For example, suppose the target letter is ' 1 '; if the first letter of the test word is ' $b$ ', the set of possible next letters includes all vowels and the consonants ' 1 ,' ' $y$,' and 'r.' However, if the first letter of the test word is 'a,' almost any consonant and a few vowels may occupy the second position. As the second set of possibilities is larger than the first, RT for ' $\mathrm{l}$ ' should be faster following the 'b.' The same is true for vowel targets; more possibilities exist following a vowel than following a consonant requiring more stimulus information. The fastest RTs should be associated with those vowel targets which follow two consonants, since the number of possibilities has been constrained further." These data from the present experiment are presented in Table 2 . If the hypothesis is correct, RTs should decrease from left to right in Table 2 for both vowels and consonants. Clearly, the expectancy hypothesis is not supported, at least in the form tested here. What, then, is the explanation for the vowel advantage?

A likely candidate is suggested by the work of Hansen and Rogers (1968). They proposed the vocalic center group (VCG) as a psycholinguistic unit for reading. The VCG is based on the work of the Haskins group on speech perception (cf. Liberman, Ingemann, Lisker, Delattre, \& Cooper, 1959), in which they present a rule set sufficient for both production and perception of speech. According to Hansen and Rogers (p.74), the VCG is the "optimally minimal sequence within which all necessary rules of phonemic co-occurrence can be stated." The VCG contains one vocalic element (which may be a dipthong), which is preceded or followed by one or more nonvocalic or semivocalic elements.

Hansen and Rogers propose a model of initial reading in which the first orthographic processing consists of marking the vowels in the word, followed by assignment of consonants to the appropriate vowels. The exact nature of the rules proposed to account for the formation of VCGs need not concern us. Evidence for the importance of the VCG in tachistoscopic recognition has recently been presented by Spoehr and Smith (1973, in press.)

The important aspect of Hansen and Rogers model for our purpose is that vowel identification precedes consonant identification. Although the search task no doubt differs from reading in important respects, it is reasonable to suppose that this particular reading skill transfers. Hence, the vowel advantage found in search of single words can be taken to support the importance of the VCG in word perception and reading.

\section{REFERENCES}

Hansen, D., \& Rogers, D. S. An exploration of psycholinguistic units in initial reading. In $\mathrm{K}$. S. Goodman, (Ed.), The psycholinguistic nature of the reading process. Detroit: Wayne University Press, 1968.

James, C. T., \& Smith, D. E. Sequential dependencies in letter search. Journal of Experimental Psychology, 1970, 85, 56-60. Kučera, H., \& Francis, W. N. Computational analysis of present-day American English. Providence, R.I: Brown University Press, 1967.

Krueger, L. E. Search time in a redundant visual display. Journal of Experimental Psychology, 1970, 83, 391-399.

Liberman, A. M., Ingemann, F., Lisker, P., Delattre, P., \& Cooper, F. Minimal rules for synthesizing speech. Journal ô the Acoustical Society of America, 1959, 31, 1490-1499.

Pillsbury, W. B. A study in apperception. American Journal of Psychology, 1897, 8, 315-393.

Reicher, G. M. Perceptual recognition as a function of meaningfulness of stimulus material. Journal of Experimental Psychology, 1969, 81, 274-280.

Spoehr, K. T., \& Smith, E. E. The role of syllables in perceptual processing. Cognitive Psychology, 1973, 5, 71-89.

Spoehr, K. T., \& Smith, E. E. The role of orthographic and phonotactic rules in perceiving letter patterns. Journal of Experimental Psychology: Human Perception and Performance, in press.

(Received for publication July 10, 1974.) 